\title{
The importance of MTHFR polymorphisms in pediatric cerebral stroke
}

\author{
Ekrem Unal • Fatma Turkan Mutlu • Musa Karakukcu
}

Received: 19 September 2011 / Accepted: 12 October 2011 /Published online: 27 October 2011

(C) Springer-Verlag 2011

\section{Dear Editor,}

We read with great interest the recent article of Arpino et al. [1] on two children with stroke associated with methylenetetrahydrofolate reductase (MTHFR) C677T and A1298C polymorphism in perinatal period. The authors reported two children presenting with presumed cerebral stroke born from two monochorionic twin pregnancies in which the other co-twin had died in utero associated to maternal and fetal homozygosity for MTHFR C677T and MTHFR A1298C, respectively.

Although the cerebral infarction is rare at childhood, the disease is still devastating to those affected. On the other hand, the etiology of cerebral infarction in about one third of the patients cannot be determined [2, 3]. Of the determined underlying causes, the polymorphisms at the genes of the enzymes involved in homocysteine metabolism may confer an increased risk for thrombosis by causing hyperhomocysteinemia. Population-based studies revealed that neither of the risk alleles (MTHFR C677T and MTHFR A1298C) of the homocysteine metabolism-related genes alone increased the risk for the occurrence of stroke [2]. Same results were obtained at Italian patients, Dragoni

E. Unal $(\bowtie) \cdot$ F. T. Mutlu $\cdot$ M. Karakukcu

Division of Pediatric Hematology and Oncology,

Department of Pediatrics, Faculty of Medicine,

Erciyes University,

Talas,

38039 Kayseri, Turkey

e-mail: drekremunal@yahoo.com.tr

E. Unal

e-mail: ekremunal@erciyes.edu.tr et al. [3] found that the prevalence of each polymorphisms were not different in patients and controls. Grabowski et al. [4] also underlined this controversy in stoke at perinatal period. Kenet et al. [5] conducted a systematic search of various electronic databases for studies published from 1970 to 2009 and found that hyperhomocysteinemia but not MTHFR polymorphisms identifies individuals at increased thrombotic risk. Both of the reported cases by Arpino et al. [1] did not show hyperhomocysteinemia, considering that the MTHFR polymorphisms do not have any effect on the cerebral stroke. As a conclusion, we would like to vigorously emphasize that MTHFR polymorphisms without hyperhomocysteinemia do not have any importance on cerebral stroke.

\section{References}

1. Arpino C, Compagnone E, Cacciatore D, Coniglio A, Castorina M, Curatolo P (2011) MTHFR C677T and A1298C polymorphisms and cerebral stroke in two twin gestations. Childs Nerv Syst 27:665-669

2. Akar N, Akar E, Ozel D, Deda G, Sipahi T (2001) Common mutations at the homocysteine metabolism pathway and pediatric stroke. Thromb Res 102:115-120

3. Dragoni F, Chiarotti F, Rosano G, Simioni P, Tormene D, Mazzucconi MG, Cafolla A, Avvisati G (2011) Thrombophilic screening in young patients $(<40$ years) with idiopathic ischemic stroke: a controlled study. Thromb Res 127:85-90

4. Grabowski EF, Buonanno FS, Krishnamoorthy K (2007) Prothrombotic risk factors in the evaluation and management of perinatal stroke. Semin Perinatol 31:243-249

5. Kenet G, Lütkhoff LK, Albisetti M et al (2010) Impact of thrombophilia on risk of arterial ischemic stroke or cerebral sinovenous thrombosis in neonates and children: a systematic review and meta-analysis of observational studies. Circulation $121: 1838-1847$ 